\title{
Research Methodology in Orthopaedics and Reconstructive Surgery
}


This page is intentionally left blank 


\title{
Research Methodology in Orthopaedics and
} Reconstructive Surgery

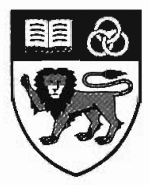

\author{
Aziz Nather \\ Department of Orthopaedic Surgery \\ National University of Singapore
}




\section{Published by}

World Scientific Publishing Co. Pte. Ltd.

P O Box 128, Farter Road, Singapore 912805

USA office: Suite 1B, 1060 Main Street, River Edge, NJ 07661

UK office: 57 Shelton Street, Covent Garden, London WC2H 9HE

\section{British Library Cataloguing-in-Publication Data}

A catalogue record for this book is available from the British Library.

\section{RESEARCH METHODOLOGY IN ORTHOPAEDICS AND RECONSTRUCTIVE SURGERY}

Copyright (C) 2002 by World Scientific Publishing Co. Pte. Ltd.

All rights reserved. This book, or parts thereof, may not be reproduced in any form or by any means, electronic or mechanical, including photocopying, recording or any information storage and retrieval system now known or to be invented, without written permission from the Publisher.

For photocopying of material in this volume, please pay a copying fee through the Copyright Clearance Center, Inc., 222 Rosewood Drive, Danvers, MA 01923, USA. In this case permission to photocopy is not required from the publisher.

ISBN 981-02-4775-3

This book is printed on acid and chlorine free paper 


\section{FOREWORD}

Experimental orthopaedics research is a new and growing field influenced by the latest development in biomechanics and molecular cell biology. These two developments have not only influenced the scientist but also the practising orthopaedics surgeons.

Professor Aziz Nather with his vast knowledge and experience in orthopaedics surgery and research has rightly embarked in editing as well as writing many chapters for his multi-authored book on Research Methodology in Orthopaedics and Reconstructive Surgery.

The publication of this book is very timely for us to remain relevant. It is interesting to note that most of the contributors are from Southeast Asia, which shows that there is expertise in this field in the region.

Conduct of research needs time and money and they should not be wasted. Good research methodology will minimise the wastage. I am sure that orthopaedics residents and young surgeons embarking on research will find this book useful.

October 16, 2001

Professor P. Balasubramaniam FRCS Eng.

Petronas Chair in Sports Medicine \& Rehabilitation

Formerly Professor of Orthopaedics Surgery

University of Malaya and National University of Singapore 
This page is intentionally left blank 


\section{PREFACE}

This book is written as a guide for residents and young orthopaedic surgeons embarking on research. It will be particularly useful to those conducting research for the very first time. In several countries in the region such as Malaysia, Indonesia, Philippines, Thailand, India and Pakistan, completing a thesis or dissertation is part of the training requirement of a resident for a masters' or fellowship degree in orthopaedic surgery. I was first invited to conduct a research seminar for residents in University Science Malaysia in Kota Bahru, Kelantan in 1994 by Dr. Hasim Mohamad. A series of lectures on how to conduct research and in particular, how to perform a thesis for a masters' degree in orthopaedic surgery was delivered. The response was overwhelming. Residents attending the seminar were trainees not only from orthopaedic surgery but also residents from other disciplines including general surgery and obstetrics and gynaecology. At their request, I conducted thesis clinics' over several days. Each trainee brought their own work for individual brainstorming session. I was indeed privileged to be consulted on research in various stages of planning ranging from those in its inception stage to those in the final stage of writing up the dissertation. It was in Kota Bahru that the idea of writing this book was born. Master students used my series of lecture notes to guide them in their preparation for their Master degree dissertation. Since then, I was invited to run similar seminars by other universities in Malaysia including University Kebangsaan Malaysia in Kuala Lumpur and by other neighbouring countries such as Indonesia.

My series of lecture notes form the core of this book notably the lectures on Planning Research (Section I), Choice of Experimental Animals (Section II), Histological Techniques and Microangiography (Section III) and the very important lectures on Writing the Finished Product (Section X). This book is designed to provide the young researcher with a detailed insight on the importance of strategic planning and the value of organising the project well before starting 
on research. The researcher must be resourceful, innovative and creative to produce good research. Even more crucial is dedication, perseverance and strong, personal commitment to pursue research. Infra-structural, technical, manpower and funding support are equally important. It also outlines the strategies that should be employed to write an application for the much needed research grant without which no research could be performed. The researcher is also advised from the very beginning to set his targets high. The resident must not just complete a thesis for the sake of passing an examination. Each research work must lead to at least one or more publications in top-ranking international refereed journals. Indeed, it should make him an expert on the topic researched upon. Researchers must strive to discover new ideas. It is hoped that from such discoveries and innovations, new techniques could develop which will revolutionalise the treatment currently available in orthopaedics and reconstructive surgery.

This mamoth task was undertaken after publication of my first book entitled "The Scientific Basis of Tissue Transplantation" released in December 2001. Despite much experienced gained from completing this book, this second book took a painstaking two years of planning, organising, writing and editing to reach completion. The journey taken was a long and arduous one. I am therefore extremely pleased that this book has at long last been completed also. Indeed, completion of this job gave me a great sense of achievement and satisfaction. I am especially glad that now I could share my research experience to others who are willing to pursue research and learn to enjoy and value research.

I wish every resident success in their quest to do research. Persevere, be committed, remain focused and one day you will succeed.

October 2001

Associate Professor Aziz Nather

Department of Orthopaedic Surgery

National University of Singapore 


\section{ACKNOWLEDGEMENT}

I would like to express my sincere gratitude to my mentor, Professor P. Balasubramaniam who not only inspired me to pursue research but also provided the much needed advice and guidance. Without his supervision, I would not have successfully completed my Doctor of Medicine Thesis: 'Revascularisation and Fracture Healing of a Large Avascular Segment of Bone. An Experimental Study in Adult Cats' in 1988.

I am extremely grateful to Mr. Yong Soon Chiong, Senior Laboratory Technologist who provided technical support for all my research work over the last 20 years. My deepest appreciation also goes to Mr. S. L. Toh, Mr. S. S. Moorthy and Mr. Tan Boon Kiat for all the excellent illustrations they have provided and to Ms. Jamaliah Baharim, Ms. S. Sarojeni, Dr. Wang Li Hui and Ms. Jane Tan Hwee Mian for all the secretarial assistance rendered over the years.

Finally, I would like to thank my wife, Suraiya and my children, Sharnaz, Zameer and Azad for their understanding, support and encouragement throughout the period taken by me for completing this book

A. Nather 
This page is intentionally left blank 


\section{CONTRIBUTORS}

Tunku Sara AHMAD, FRCS (Glas), AM

Associate Professor

Head, Department of Orthopaedic Surgery

University of Malaya

Kuala Lumpur, Malaysia

Darina BAČENKOVÁ, Mgr

Tissue Bank

Faculty of Medicine Pavol Jozef Šafárik

University and University Hospital

Trieda SNP1

04066 Košice, Slovakia

Alberto N. BOLGIANI, MD, FRCS

Surgeon

Burn and Trauma Surgery

Fundacion Benaim Alberti 1093

1223 Buenos Aires, Argentina

John CHIA, FRCS (Ed), FAMS

Assistant Professor

Department of Orthopaedic Surgery

National University of Singapore

10 Kent Ridge Crescent

Singapore 119260

Victoria, Yuen Yee CHENG, BSc

Department of Orthopaedics \& Traumatology

The Chinese University of Hong Kong

Shatin, NT, Hong Kong, China 
CHIA Kee Seng, MSC (OM), MD

Associate Professor

Department of Community, Occupational \& Family Medicine Faculty of Medicine, National University of Singapore 10 Kent Ridge Crescent

Singapore 119260

Louis, T. C. CHOW, MD, MR (Path)

Department of Orthopaedics \& Traumatology

The Chinese University of Hong Kong,

Shatin, NT, Hong Kong, China

Shamal DAS DE, MB, BS, FRCS (Ed), FRCS (Eng), FRCS (Orth) (Ed), $\mathrm{MCH}$ (Orth) (Liv), MD (Sing), FAMS (Sing)

Professor

Department of Orthopaedic Surgery

National University of Singapore

10 Kent Ridge Crescent

Singapore 119260

Anna DZIEDZIC-GOCLAWSKA, MD, PhD

Professor

Department of Transplantology \&

Central Tissue Bank Centre of Biostructure

The Medical University of Warsaw

Ul. Chalubinskiego 5, 02-004 Warsaw, Poland

FU L.K. MBBS, MPhil

Department of Orthopaedics \& Traumatology

The Chinese University of Hong Kong

Shatin NT, Hong Kong, China 
Ahmad Sukari HALIM, MD, FCCP

Plastic \& Reconstructive Surgery Unit

Department of Surgery, School of Medical Sciences

Universiti Sains Malaysia

16150 Kota Bharu, Kelantan, Malaysia

HEE Hwan Tak, FRCS (Ed), FRCS (Glas), FAMS

Department of Orthopaedic Surgery

National University of Singapore

10 Kent Ridge Crescent

Singapore 119260

Helga HRBROVÁ, Ing

Tissue Bank

Faculty of Medicine Pavol Jozef Šafárik

University and University Hospital

Trieda SNP1

04066 Košice, Slovakia

Sharaf IBRAHIM, MD, FRCS, MS (UKM)

Associate Professor and Paediatric Orthopaedic Surgeon

Department of Orthopaedics and Traumatology

Hospital Universiti Kebangsaan Malaysia,

Cheras, 56000 Kuala Lumpur, Malaysia

Wan Faisham ISMAIL, MMed, MD

Department of Orthopaedics

School of Medical Sciences

Universiti Sains Malaysia

16150 Kota Bharu, Kelantan, Malaysia

Andrej Jenča, MD

Department of Maxillofacial Surgery

Faculty of Medicine Pavol Jozef Šafárik

University and Louis Pasteur University Hospital

Ratrslavova 43, 04001 Košice, Slovakia 
Artur KAMINSKI, MD, PhD

Assistant Professor

Department of Transplantology \& Central Tissue Bank

Center of Biostructure Research

Medical University of Warsaw

ul. Chalubinskiego 5, 02-004 Warsaw, Poland

KANG Yang Koo, MD, PhD

Professor

Department of Orthopaedic Surgery

Catholic University Medical College

St. Vincent's Hospital

Suwon, 440-060, Korea

Shekhar M. KUMTA, MS (Orth), PhD

Associate Professor

Department of Orthopaedics \& Traumatology

The Chinese University of Hong Kong

Shatin NT, Hong Kong, China

P.C. LEUNG, FRCS, DSC

Department of Orthopaedics \& Traumatology

The Chinese University of Hong Kong

Shatin NT, Hong Kong, China

Wojciech J. MARCZYNSKI, MD, PhD

Professor and Head of Children Orthopaedic Clinik

University Teaching Hospital

Military Medical Academy

Str. Szaserow 128, 00-909 Warsaw, Poland

Nor Azman MAT ZIN, MD, BSc

Department of Orthopaedics

School of Medical Sciences, Universiti Sains Malaysia

16150 Kota Bharu, Kelantan, Malaysia 
Ryuji MORI, MD

Assistant Professor

Department of Orthopaedic Surgery, Shimane Medical University, 89-1 Enya-cho Izumo City

Shimane 693-8501, Japan

Aidura MUSTAPA, MMed, MD

Department of Orthopaedics

School of Medical Sciences, Universiti Sains Malaysia

16150 Kota Bharu, Kelantan, Malaysia

Aziz NATHER, FRCS (Ed), MD

Associate Professor

Department of Orthopaedic Surgery

National University of Singapore

10 Kent Ridge Crescent

Singapore 119260

Mitsuo OICHI, MD, PhD

Professor

Department of Orthopaedic Surgery

Shimane Medical University

89-1 Enya-cho Izumo City

Shimane 693-8501, Japan

In Young $\mathrm{OK}, \mathrm{MD}, \mathrm{PhD}$

Professor

Department of Orthopaedic Surgery

Kang-Nam St. Mary's Hospital

The Catholic University of Korea

College of Medicine

505 Banpo-dong, Seocho-ku

Seoul, 137-040, Korea 
Barry PEREIRA, MEng

Research Fellow

Department of Orthopaedic Surgery

National University of Singapore

I0 Kent Ridge Crescent

Singapore 119260

B. PRIJAMBODO, MD, DR (Sci), FICS, FCSRS

Professor

Spine Section, Dept. of Orthopaedic Surgery

School of Medicine Airlangga University

Dr. Soetomo Teaching Hospital

Surabaya, Indonesia

Ján ROSOCHA, DVM, CSc

Head of Associated Tissue Bank

Faculty of Medicine Pavol Jozef Šafárik

University and University Hospital

Trieda SNP 1

04066 Košice, Slovakia

Jong-Won RHIE, MD, PHD

Department of Plastic Surgery

St. Mary's Hospital, The Cartholic University of Korea, 62, Yoido-dong, Youngdeungpo-Ku

Seoul, Korea 150-713

Seok-Whan SONG, MD, DMSc

Surgeon

Department of Orthopaedic Surgery,

St. Mary's Hospital, The Catholic University of Korea

62, Yoido-dong, Youngdeungpo-Ku

Seoul, Korea 150-713 
Robert Švihla, MD

Department of Orthopaedics, Faculty of

Medicine Pavol Jozef Šafárik University and University Hospital, Trieda SNP 1

04066 Košice, Slovakia

Gabriel VAŠKO, MD, CSc

Associate Professor

Department of Orthopaedics, Faculty of

Medicine Pavol Jozef Šafárik University and

University Hospital, Trieda SNP 1

04066 Košice, Slovakia

Wilson WANG, MB, BS, FRCS, DPhil

Assistant Professor

Department of Orthopaedic Surgery

National University of Singapore

10 Kent Ridge Crescent

Singapore 119260

YONG Soon Chiong

Senior Laboratory Officer

Department of Orthopaedic Surgery

National University of Singapore

10 Kent Ridge Crescent

Singapore 119260

Ming Hao ZHENG, PhD (WA) MRCPath (UK), MD (WA)

Associate Professor

Department of Surgery (Orthopaedics)

University of Western Australia

QEII Medical Centre

$2^{\text {nd }}$ Floor M Block

Nedlands, WA 6009, Australia 
ZULMI Wan, MS (Ortho), MBBS

Associate Professor \& Head

Department of Orthopaedics, School of Medical Sciences

Universiti Sains Malaysia

ह. 16150 Kota Bharu, Kelantan, Malaysia 


\title{
INTRODUCTION
}

\author{
AZIZ NATHER \\ MBBS, FRCS (Ed), FRCS (G), AM, MD \\ Associate Professor \\ Department of Orthopaedic Surgery \\ National University of Singapore
}

This book is organised into ten sections, ranging from Section I on 'Planning Research' to Section X on 'Writing the Finished Product'. It is intended to provide a comprehensive guide on how to conduct research.

\section{Section I: Planning Research}

Detailed planning is the key to success in any research. Factors that must be considered during the initial planning stage include presence of good supervision, critical review of existing literature on the problem, originality of the work, clarity of the objectives set out in the study, the supporting infrastructure and manpower available and ethical considerations involved. These issues are discussed in Chapter 1.

With the keen competition present and limited funds available, it is becoming increasingly difficult to secure research grants. In Chapter 2, the author gives valuable tips on how to write an application for a grant. Aspects covered include choosing the appropriate title, how to write a good abstract, defining the specific aims indicating clearly their clinical significance and writing the Materials and Methods section in sufficient detail. Providing a 
realistic budget estimation is critical. The latter reflects the researcher's maturity and ability to conduct the research.

\section{Section II: Animal Experimental Surgery}

The choice of laboratory animal and the research model to be used are critical to the success and significance of the research as a whole. Chapter 3 discusses the important issues involved ranging from animal used by the previous workers, evolutionary status of the animal chosen, animal holding facilities available to support animal experimentation and the availability and costs of the animals themselves. The time allocated for research is also critical. It is essential to conduct a pilot study to assess feasibility of the research before the full scale project is launched.

The availability of a purpose-built Animal Holding Facility is extremely important to support animal experimentation. Chapter 4 describes the features that should be included in the construction of such a unit ranging from sound-proofing of rooms, design of floors, drainage system to waste disposal area. Such a facility must have well-designed operating rooms equipped with the latest facilities as well as an X-ray room equipped with a portable X-ray machine. The author further describes the caging, dietary requirements and environmental conditions required for various animals including mice, rats, rabbits, cats, dogs, sheep, goats, pigs and monkeys.

For humane reasons, the animal must be given proper analgesia or anaesthesia to allow the operation to be performed well. Chapter 5 outlines the pre-operative preparation required, the type of anaesthesia that should be used as well as the post-operative regime to provide pain relief. An anaesthetic machine must be available, as well as experienced personnel to run this equipment. The anaesthetic regimes used for various animals including rats, rabbits, cats, dogs, sheep, goats, pigs and monkeys are outlined. 


\section{Section III: Histological \& Other Specialised Techniques}

Several projects requiring histological preparation go to waste because the investigators are not familiar with the appropriate fixative that should be used upon specimen procurement for decalcified bone sections, undecalcified bone sectioning or for electron microscopy. Chapter 6 deals with the various fixatives used for tissue preservation. Chapter 7 outlines the processing techniques involved for producing decalcified bone sections. In Chapter 8 , processing for undecalcified bone sectioning is described including the special staining methods to be employed for such resin-embedded specimens. Preparation of sections for transmission and scanning electron microscopy is described in Chapter 9.

Histomorphometry - the quantitation of tissue elements on histological sections is useful to allow quantitation of various tissue and cellular elements including bone resortion, new bone formation, callus encasement, osteocyte count, chondrocyte count, etc. Chapter 10 describes histomorphometry using computer software - computerised morphometry and the set-up required for such data analysis.

In Chapter 11, the author highlights the use of microangiography using barium sulphate (Rhinelander's perfusion technique) to study the blood supply of bone and soft tissues. A 'revascularisation index' is described to quantitate the vascularity of bone.

Every department needs a medical illustration unit not only for research but more so for teaching. In the past, such a unit required space, manual cameras and darkroom facilities for processing of black and white prints and diazochrome slides. With the advance of digital technology such facilities have become obsolete. In Chapter 12, the author describes the setting up of a photographic unit using digital technology. The basic equipment required include digital camera, PC, scanner, etc. This new technology saves time, space and costs. 


\section{Section IV: Biology of Healing of Musculo-Skeletal Tissues}

Using histomorphometry, Nather provides a description of the biology of healing occurring in massive, non-vascularised, cortical autografts and in massive cortical allografts using the tibial model in adult cats in Chapter 13. Decalcified bone sections were studied. In the following chapter, Nather quantitated the revascularisation index of similar autografts and allografts in the same feline, tibial model.

Marczynski evaluated bone graft remodelling semi-quantitatively in Chapter 15 using a 6-grade scale system. In Chapter 16, Dziedzic-Goclawska describes the employment of computerised morphometry to evaluate the osteoinductive properties of decalcified bone allografts. The model of heterotopically induced osteogenesis in rats was used.

\section{Section V: Biomechanics of Musculo-Skeletal Tissues}

Chapter 17 written by a bioengineer outlines the basic concepts in biomechanics for both structural and material properties of tissues. This is followed by Nather's description of the biomechanics of healing of massive, non-vascularised, cortical autografts and massive, cortical allografts using the same tibial model in adult cats.

\section{Section VI: Research in Microvascular Surgery}

This section begins with a chapter outling the preparation required for a resident training to acquire the necessary skills required to perform research using microvascular surgery. The author describes a curriculum of 6 practical exercises using rats. Only after mastering these exercises is the resident ready to conduct microvascular research.

In Chapter 20, Zulmi et al. describes their clinical experience with using vascularised fibula transplants. A variety of methods including several, segmented, cortical osteotomies and single osteotomy 
were employed. Their experience with using Capanna's "allograft shell plus vascularised fibula composite" is also reported.

In Chapter 21, the authors gives a review of the literature on research for microvascular flaps. They highlight the importance of monitoring flap perfusion using new techniques. There is much potential to perform research on flap perfusion.

Chapter 22 written by Kumta et al. deals with the immunological behaviour of massive allografts. They showed that intra-medullary implantation of a blood vessel into an allograft led to slow revascularisation. This did not elicit a host-immune response. Kumta explored the possibility of using immunosuppression to prevent rejection of massive, vascularised allografts. More research could be done to modulate immunologically either the massive allograft or the host.

\section{Section VII: Tissue Engineering \& Cell Culture}

With the current revolution of tissue engineering and gene modulation, this book would be incomplete without a good section on tissue engineering and cell culture in orthopaedics \& reconstructive surgery. In Chapter 23, Zheng presents an overview of cell-based tissue engineering in orthopaedic surgery including chondrocyte, myoblast and tendocyte transfer therapy and mesenchymal stem cell therapy. He presented his techniques of culturing human chondrocytes, myoblasts and tendocytes, as well as mesenchymal stem cells.

In Chapter 24, Rosocha et al. describes their technique of culturing human osteocytes and their prelimary results of the clinical applications of such cells. Ok in Chapter 25 describes the facilities required to perform chondrocyte culture and their protocol for culturing chondrocytes from articular cartilage. He also discusses the future directions of autologous human chondrocyte transplantation.

In Chapter 26, Bolgiani discusses keratinocyte culture, techniques involved and the use of laser skin as a delivery system for cultured 
keratinocytes. He also discusses the future directions of tissue engineered skin.

This section ends with a chapter by Kumta on banking tumour cells including organisation and structure required, techniques involved, retrieval and storage protocols, safety issues and medicolegal considerations. Banked tumour cells provide valuable resource materials for research into molecular genetic manifestation of tumours and the potential treatment of such tumours by gene manipulation techniques.

\section{Section VIII: Cadaveric Research}

Cadaveric dissection is a useful tool for research. It enriches our knowledge on human gross anatomy for orthopaedic \& reconstructive surgery. In Chapter 28, the author describes the facilities required to carry out cadaveric dissection. The resident could be taken through three levels of cadaveric study. This chapter focuses on dissections in the upper limb and outlines 7 tutorials including (1) bone, (2) elbow, (3) forearm, (4) hand, (5) nerves and vessels, (6) brachial plexus and (7) blood vessels, that should be followed by residents taking up hand surgery.

In Chapter 29, the author presents his experience of using Batson's technique for studying vascularity of musculo-skeletal tissues in human cadavers. His studies focused on vascularity of tissues in the lower limb.

\section{Section IX: Opportunities in Clinical Research}

Research plays a vital role in the training of an orthopaedic resident. It enables the resident to think laterally and identify potential areas of clinical significance which could be investigated in a quantitative, analytical and deductive manner. In Chapter 30, the author emphasises the value the value of research in the orthopaedic training programme. It makes the resident a better surgeon. 
It is also through research that new discoveries and new techniques evolve to provide better care for our patients.

In the next chapter, the authors describe the new frontiers in spine surgery ranging from interbody cages, minimally invasive surgery, IDET, vertebroplasty and kyphoplasty, bone substitutes, autologous growth factors, spinal cord regeneration and gene therapy for spinal fusion. This tremendous expansion of new technology far exceeds that seen in any other discipline in orthopaedic surgery. Such a scenario present numerous opportunities to the young researcher to conduct both basic and clinical research in the several, new, evolving frontiers in spine surgery. Indeed, the research environment in spine surgery is keenly competitive. The race for searching even more innovative techniques is extremely intense.

In hip surgery, the new advances are mainly in the development of improved surgical techniques and in the development of biomaterials. The authors highlighted these potential areas of research interest in Chapter 32.

For knee surgery, the areas of research interest pin-pointed in Chapter 33 included research on cartilage, ligament and meniscus. The most significant area evolved to date is the transplantation of autologous cultured chondrocytes.

Chapter 34 deals with the areas that merit attention in paediatric orthopaedics. These include certain fractures, bone and joint infections, osteogenesis imperfecta, clubfoot, developmental dysplasia of the hip, slipped upper femoral epiphysis and Perthes disease.

In Chapter 35, the author identifies topics for research in hand surgery. Areas for clinical research include skeletal trauma and reconstruction, new techniques for fixation of scaphoid fractures, types of reconstruction of the distal radio-ulnar joint, soft tissue trauma and reconstruction and various flap techniques and tendon repair including gene therapy for cultured tendocytes.

With regards to orthopaedic oncology, Chapter 36 outlines the potential areas of clinical research to be radiologic and pathologic studies, biopsy and staging, chemotherapy, surgical resection and the efficacy of various reconstructive procedures ranging from 
autograft transplantation, allograft transplantation to the use of prosthesis.

In Chapter 37, the author identifies the opportunities to be studying the role of the various growth factors for skin healing. These include platelet-derived growth factors, TGF-B, vascular endothelial growth factor, basic fibroblast growth factor, epidermal growth factor and other growth enhancing agents. A big challenge is to design a delivery system for delivering the various factors to wounds by gene therapy.

\section{Section X: Writing the Finished Product}

Chapter 38 describes the basic concepts in statistics to provide a framework for data analysis and interpretation. Aspects covered include study designs, sources of errors, types of variables, summarising data, discovering simple relationship and unravelling complex ones.

Writing the Finished Product is indeed the most important part of research. Targets must be set high. All research should produce at least one if not more publications in a top-ranking international refereed journal. It is common to see investigators not producing any publication at all. The work is merely presented as Conference Papers. This is not at all satisfactory. Dissertations must be done not just to pass Post-Graduate Examinations. They should lead to publications in journals of international recognition.

In Chapter 39, the author guides the young researcher to make the right choice for selecting the Journal the written product should be submitted to. The article must be an original article and not a review article. Issues covered include authorship, good writing, strategies to be employed for writing the various sections - Introduction, Materials and Methods, Results, Discussion, Abstract, Title Page and Bibliography. He stresses the importance of self editing and editing by independent individuals and revision of the completed manuscript several times before arriving at the final product. 
In the next chapter, the author recommends different strategies that could be adopted in writing a thesis or a dissertation. Each section is best written separately as a module. It is important to collect, caption and catalogue valuable illustrations chosen from the start of the research. The format for writing the thesis must be followed in the final assembly of all the modules to make up the thesis - Title Page, Abstract, Contents, Introduction, Review of Literature, Materials and Methods, Results, Discussion, Conclusions, Bibliography and Acknowledgement. However, the author recommends writing the thesis using the following chronological sequence: Title Page, Materials and Methods, Results, Conclusions, Review of Literature, Discussion, Introduction, Bibliography and Abstract. The thesis must be edited by the researcher and by independent persons several times and revised accordingly to reduce the number of errors.

In Chapter 41, the author reveals the editorial process that occurs once an article is received by the Journal's Editorial Office. If all instructions have been complied with, the article is classified and presented to the Editorial Committee. Two appropriate reviewers are then selected. Criteria assessed by reviewers include general criteria - originality, presentation, length of article, illustrations used, references appended and abstract/keywords presented. Scientific criteria evaluated include objectives of study, materials used, methodology employed, results derived, conclusions drawn and the clinical significance of the work presented. The typical format used for editing the article and the type of recommendations made are also discussed.

It is useful to know what an Examiner looks for in a thesis. In Chapter 42, the author discloses the qualifications a University looks for in an External Examiner and the responsibilities and requirements the latter must fulfil before he is contracted to do the assessment. The evaluation includes general assessment - profile of student, his department and his supervisors. The major considerations upon which a thesis is judged include objectives achieved, materials used, methodology employed, results presented and 
conclusions drawn. In the final analysis, the originality of the work and its clinical significance are the most important parameters assessed. The typical format for evaluating a thesis and the usual overall recommendations made by an External Examiner are presented. It is important to recognise that a higher standard is expected for a $\mathrm{PhD}, \mathrm{MD}$ or DDS degree compared to that required for an MSc degree.

Very often, the research output of an academic is assessed mainly on the list of publications he has achieved and in particular only those publications in high-ranking international refereed journals. This is a myopic approach. Even contributions of valuable chapters in books are sometimes not considered. In the last chapter of this book, the author describes how total objective evaluation of an individual's research output should be performed. Five criteria should be used - publications written, research grants obtained, research awards received, membership on research committees and finally the peer review itself. 


\section{CONTENTS}

Foreword

Preface

Acknowledgement

vii

Contributors

Introduction

Section I: Planning Research

1 Planning a Research Project

A. Nather

2 Writing Up an Application for a Research Project

A. Nather

Section II: Animal Experimental Surgery

3 Choice of Experimental Animals

A. Nather

4 Care and Handling of Laboratory Animals

S.C. Yong

5 Anaesthesia for Animals

S.C. Yong

Section III: Histological \& Other Specialised Techniques

6 Fixatives for Preservation of Tissues

S.C. Yong \& A. Nather

7 Preparation, Processing, Sectioning \& Staining of

Decalcified Bone

S.C. Yong \& A. Nather 
8 Preparation, Processing, Sectioning \& Staining of Undecalcified Bone

S.C. Yong \& A. Nather

9 Preparation, Processing, Sectioning \& Staining for Electron Microscopy

S.C. Yong

10 Histomorphometry of Bone

A. Dziedzic-Goclawska \& A. Kaminski

11 Microangiography

A. Nather

12 Setting Up Medical Illustrations Unit Using Digital Technology

S.C. Yong

\section{Section IV: Biology of Healing of Musculo-Skeletal}

Tissues

13 Biology of Healing of Bone Transplantation -

Autografts \& Allografts. A Histomorphometric Study

A. Nather

14 Revascularisation of Bone Transplantation -

Autografts \& Allografts. A Microangiographic Analysis 234 A. Nather

15 Semi-Quantitative Evaluation of Bone Graft Remodelling

W.J. Marczynski

16 Evaluation of Osteoinductive Potential of Bone Grafts 263 A. Dziedzic-Goclawska

Section V: Biomechanics of Musculo-Skeletal Tissue

17 Basic Concepts in Biomechanics: Structural \& Material Properties B.P. Pereira 
18 Biomechanics of Healing of Bone Transplantation Vascularised Autografts, Non-Vascularised Autografts \& Allografts A. Nather

Section VI: Research in Microvascular Surgery

19 Preparation for Research in Microvascular Surgery S.C. Yong

20 Clinical Research in Microvascular Surgery W. Zulmi, A. Mustapa, W.F. Ismail, N.A. Mat Zin \& A.S. Halim

21 Research in Microvascular Flaps S.W. Song \& and J.W. Rhie

22 Bone Allotransplantation - Future Directions

S. Kumta, P.C. Leung \& L.K. Fu

Section VII: Tissue Engineering \& Cell Culture

23 Cell-Based Tissue Engineering

M.H. Zheng

24 Human Osteoblasts Culture - Methodology \&

Clinical Applications

J. Rosocha, D. Bačenková, H. Hrbková, G. Vaško,

R. Švihla \& A. Jenča

25 Chondrocyte Culture

I. Y. OK

26 Keratinocytes Culture

A.N. Bolgiani

27 The Tumour Tissue Bank

S. Kumta, T.C. Chow \& Y.Y. Cheng 
Section VIII: Cadaveric Research

28 Cadaveric Dissection in the Upper Limb 501 J. Chia

29 Batson's Compound Technique for Studying Vasculature of Musculo-Skeletal Tissues in Cadavers S. Das De

\section{Section IX: Opportunities in Clinical Research}

30 Role of Research in the Orthopaedic Training Programme

B. Prijambodo

31 New Frontiers in Spinal Surgery

A. Nather \& H.T. Hee

32 New Frontiers in Hip Surgery \& Research

Opportunities

W. Wang \& S. Das De

33 Research in Knee Surgery - Cartilage Ligament \& Meniscus

M. Ochi \& R. Mori

34 Research in Paediatric Orthopaedics S. Ibrahim

35 Research in Hand Surgery T. S. Ahmad

36 Research in Orthopaedic Oncology Y.K. Kang

37 Research in Skin Healing 
Section X: Writing The Finished Product

38 Statistical Evaluation K.S. Chia

39 Writing the Finished Product: An Article for a Journal 712 A. Nather

40 Writing the Finished Product: A Thesis or Dissertation 724 A. Nather

41 Editing an Article

A. Nather

42 Examining a Thesis or Dissertation

A. Nather

43 Total Objective Evaluation of Research Output

A. Nather

Index 